\title{
Rapid and sudden advection of warm and dry air in the Mediterranean Basin
}

\author{
J. Mazon ${ }^{1}$, D. Pino ${ }^{1,2}$, and M. Barriendos ${ }^{3,4}$ \\ ${ }^{1}$ Department of Applied Physics, Universitat Politècnica de Cataluna, BarcelonaTech, Barcelona, Spain \\ ${ }^{2}$ Institute for Space Studies of Catalonia (IEEC-UPC), Barcelona, Spain \\ ${ }^{3}$ Institut Català de Ciències del Clima (IC3), Barcelona, Spain \\ ${ }^{4}$ Department of Modern History, University of Barcelona, Barcelona, Spain
}

Correspondence to: J. Mazon (jordi.mazon@upc.edu)

Received: 21 May 2013 - Published in Nat. Hazards Earth Syst. Sci. Discuss.: 2 August 2013

Revised: 22 November 2013 - Accepted: 9 January 2014 - Published: 14 February 2014

\begin{abstract}
Rapid advection of extremely warm and dry air is studied during two events in the Mediterranean Basin. On 27 August 2010 a rapid advection of extremely warm and dry air affected the northeast Iberian Peninsula during a few hours. At the Barcelona city center, the temperature reached $39.3{ }^{\circ} \mathrm{C}$, which is the maximum temperature value recorded during $230 \mathrm{yr}$ of daily data series. On 23 March 2008 a rapid increase of temperature and drop of relative humidity were recorded for a few hours in Heraklion (Crete). During the morning on that day, the recorded temperature reached $34^{\circ} \mathrm{C}$ for several hours on the northern coastline of this island.

According to the World Meteorological Organization none of these events can be classified as a heat wave, which requires at least two days of abnormally high temperatures; neither are they a heat burst as defined by the American Meteorological Society, where abnormal temperatures take place during a few minutes. For this reason, we suggest naming this type of event flash heat.

By using data from automatic weather stations in the Barcelona and Heraklion area and WRF mesoscale numerical simulations, these events are analyzed. Additionally, the primary risks and possible impacts on several fields are presented.
\end{abstract}

\section{Introduction}

The World Meteorological Organization (WMO) defines a heat wave as a phenomenon in which the daily maximum temperature of more than five consecutive days exceeds the average maximum temperature by $5{ }^{\circ} \mathrm{C}$, with respect to the period 1961-1990 (Frich et al., 2012). The glossary of meteorology of the American Meteorological Society (AMETSOC, Glickman, 2000) defines a heat wave as a period of abnormally and uncomfortably hot and usually humid weather, which should last at least 1 day, but conventionally lasts from several days to several weeks. The definition presents slight variations in the values of exceeded temperature with respect to the average temperature depending on the national weather service. However, a common characteristic is found in all regional definitions: speaking about a heat wave requires a duration of at least 2 consecutive days of abnormal temperature values. Thus, heat waves are considered a synoptic phenomenon that cover several thousands of square kilometers and last at least 2 or more days.

Many authors have studied the dynamics of heat waves and their effects in several fields, such as agriculture (Jolly et al., 2005), human health (Smoyer-Tomic et al., 2003; Meehl and Tebald, 2004), or discomfort (Matzarakis and Nastos, 2010; Nastos and Matzarakis, 2012), tourism (Steadman, 1984; Hamilton et al., 2005; Lise and Tol, 2002), energy consumption (Karl and Quayle, 1981; Hassid et al., 2000) and water demand (Smoyer-Tomic et al., 2003). Furthermore, some studies (Meehl and Tebald, 2004; Trenberth et al., 2007) show that an increase in intensity, frequency and the duration of heat waves around the earth will occur during the 21 st century. In all scenarios shown in the 4th IPCC report (Trenberth et al., 2007), the Mediterranean Basin will be one of the most significant regions affected by an increase in both the intensity and frequency of heat waves during this century. 
Table 1. Three different scales of events linked to abnormally high temperatures. The scales are adapted from Orlanski (1975).

\begin{tabular}{llll}
\hline Event & Temporal scale & Spatial scale & Driving mechanism \\
\hline Heat wave & From 2 to few weeks & Meso- $\alpha(200-2000 \mathrm{~km})$ & General atmospheric circulation \\
Heat burst & Few minutes & Micro- $\beta, \gamma(<2 \mathrm{~km})$ & Thunderstorms \\
Flash heat & $1-24 \mathrm{~h}$ & Meso- $\beta, \gamma(20-200 \mathrm{~km})$ & General atmospheric circulation, Foehn effect \\
\hline
\end{tabular}

If a smaller scale is considered, the glossary of AMETSOC defines a heat burst as a rare atmospheric event characterized by gusty winds, rapid temperature increase, and a decrease in relative humidity, typically occurring at night or early morning (Johnson, 1976; Glickman, 2000). It is usually associated with descending air during a thunderstorm. The typical timescale of heat burst is a few minutes, less than an hour. Recorded temperatures during heat bursts have reached well above $32{ }^{\circ} \mathrm{C}$, sometimes rising by $11^{\circ} \mathrm{C}$ or more within only a few minutes.

This paper aims to study two events associated with an increase in temperature and decrease in relative humidity occurring at intermediate temporal and spatial scales. We will call this phenomenon flash heat, because it occurs within a timescale shorter than a heat wave but longer than a heat burst. This event is usually associated with an adiabatic warming of downslope winds, associated with Foehn effect (Maninns and Sawford, 1979; Egger and Hoinka, 1992; Wakonigg, 1990). To our knowledge, there is no previous scientific reference naming this type of events.

Table 1 summarizes the differences between the three types of abnormal high temperature events mentioned above. Note the different spatial and temporal scales of flash heat, as well as the dynamics of its formation.

The structure of this paper is as follows. Section 2 is devoted to analyzing and describing, by using observations and mesoscale model numerical simulations, the 27 August 2010 event in the northeast of the Iberian Peninsula, where a very warm and dry air mass affected this area over $8 \mathrm{~h}$. It focuses on the Barcelona area, where the maximum daily temperature in over $230 \mathrm{yr}$ was recorded. According to this analysis, a preliminary flash heat definition is proposed in order to analyze the existence of similar flash heat events during the 19th century in the daily temperature series of Barcelona (1790-2012). The rapid increase of temperature and decrease of relative humidity occurred on 23 March 2008 in Heraklion (Crete island) is analyzed in Sect. 3. In Sect. 4 we describe the main impacts that this event could produce on several fields, mainly in agriculture, energy demand, health and fires. Finally, in Sect. 5 the main conclusions are presented.

\section{The 27 August 2010 event (Barcelona event)}

According to the Agency of Spanish Meteorology (AEMET), the summer of 2010 was the third warmest summer recorded in the Iberian Peninsula. Particularly, August 2010 was the fifth warmest month since 1971; its mean temperature was $1.5^{\circ} \mathrm{C}$ higher than the average monthly temperature and it was the third warmest month in this century. To the south and east of the Iberian Peninsula, maximum temperatures between 40 and $44^{\circ} \mathrm{C}$ were recorded. Minimum early morning temperatures of between 23 and $26^{\circ} \mathrm{C}$ were recorded by several official AEMET weather stations during this period.

However, the heat wave does not affect the north and northeast Iberian Peninsula. The warm and dry air mass was almost stationary, affecting the entire center and southern part of the Iberian Peninsula. However, a rapid and brief movement of this warm air mass from the southeast to northeast on 27 August 2010 affected the northeast Iberian Peninsula for several hours, when a significant increase in temperature was recorded as well as a decrease in the relative and absolute humidity. Automatic weather stations located in the Barcelona city center recorded $39.3^{\circ} \mathrm{C}$ (the highest temperature since 1780 ) and the relative humidity dropped to $19 \%$. In addition, the recorded temperature values from 11:00 to 16:00 UTC were above $30^{\circ} \mathrm{C}$, more than $5^{\circ} \mathrm{C}$ higher than the mean maximum temperature in August during the period 1961-1990, which was $26.8^{\circ} \mathrm{C}$. However, for the $12 \mathrm{~h}$ prior to and later than the hours in which the maximum value was recorded, the temperature remained within normal values. As will be shown, the period of abnormally high temperature could be considered as occurring from 11:00 to 16:00 UTC. This event cannot be classified according to the above definitions either as a heat wave or as a heat burst.

\subsection{Synoptic situation}

Figure 1 shows the temperature at $850 \mathrm{hPa}$ obtained by the reanalysis of the National Centers of Environmental Prediction (NCEP) at 00:00 UTC from 26 to 28 August 2010. A ridge from North Africa remained stationary in northwest Africa for a few days before 25 August 2010, when it began to move to the north. On 25 August at 00:00 UTC (not shown), the $25^{\circ} \mathrm{C}$ isotherm at $850 \mathrm{hPa}$ was located at the southern Iberian Peninsula and a large anticyclonic ridge was located in northwest Africa. Over the northern third of the Iberian Peninsula the $850-\mathrm{hPa}$ isotherm was $15^{\circ} \mathrm{C}$ at 00:00 UTC. On 26 August, the ridge moved to the north. At $850 \mathrm{hPa}$ (see Fig. 1a), the $25^{\circ} \mathrm{C}$ isotherm was in the central and southern Iberian Peninsula. On 27 August, at 00:00 UTC (Fig. 1b), the ridge $\left(25^{\circ} \mathrm{C}\right.$ isotherm at $\left.850 \mathrm{hPa}\right)$ extended from the southwest to the northeast of the Iberian Peninsula, and moved 

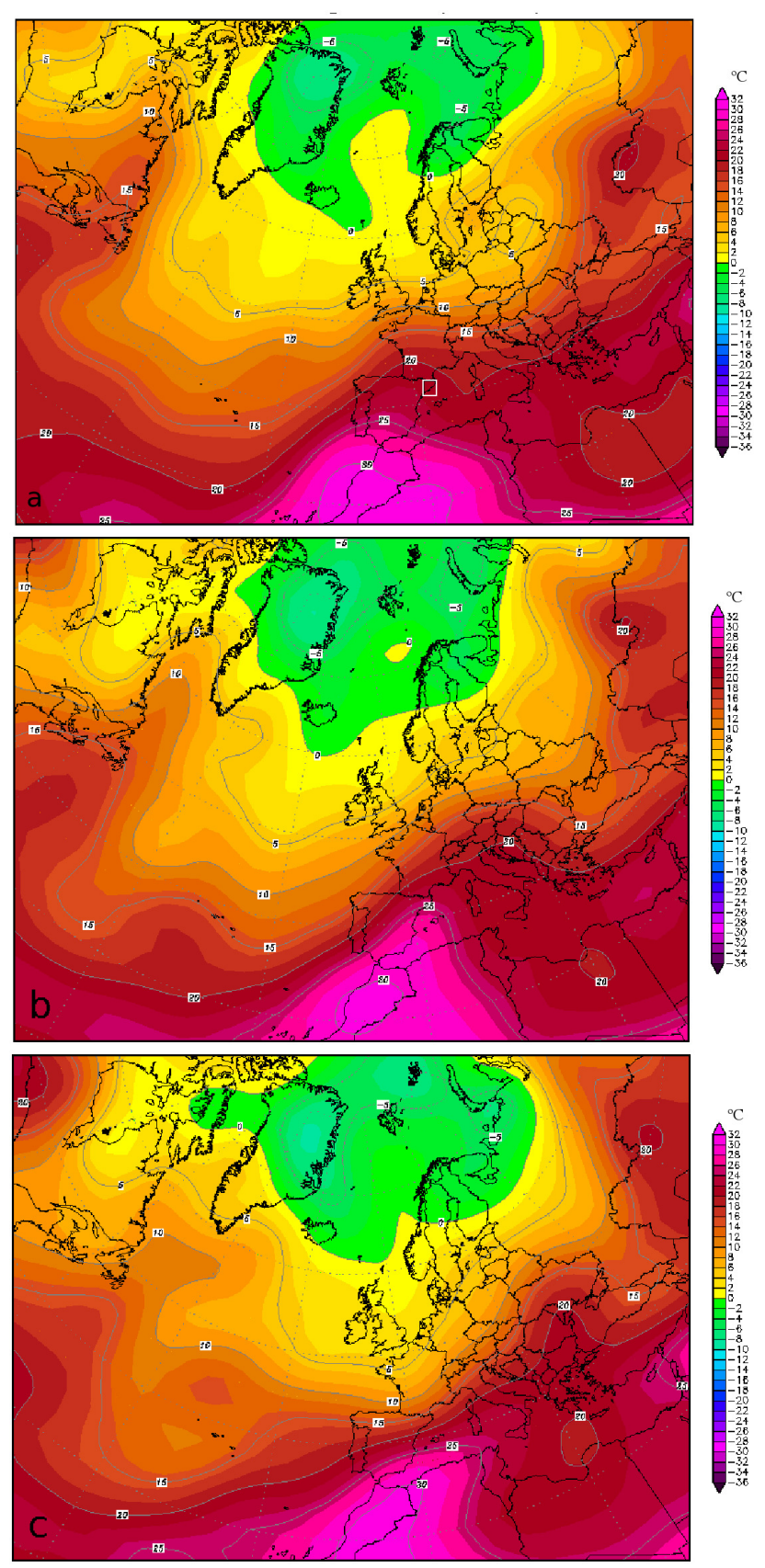

Fig. 1. Temperature at $850 \mathrm{hPa}$ obtained by the NCEP reanalysis at 00:00 UTC on (a) 26, (b) 27 and (c) 28 August 2010. The white square in (a) is centered over the first area under study.

rapidly to the southeast, displaced by a northeast advection. On 28 August, at 00:00 UTC (see Fig. 1c), the border of the $25^{\circ} \mathrm{C}$ isotherm at $850 \mathrm{hPa}$ was displaced to the southeast of the Iberian Peninsula. The $15^{\circ} \mathrm{C}$ isotherm at $850 \mathrm{hPa}$ approximately followed the Pyrenees Mountains. On 29 August the northeast advection increased, with a $10^{\circ} \mathrm{C}$ isotherm at $850 \mathrm{hPa}$ at 00:00 UTC over the Pyrenees (not shown). Several storms formed in the northeast Pyrenees during those days. In the south and southeast of the Iberian Peninsula, the heat
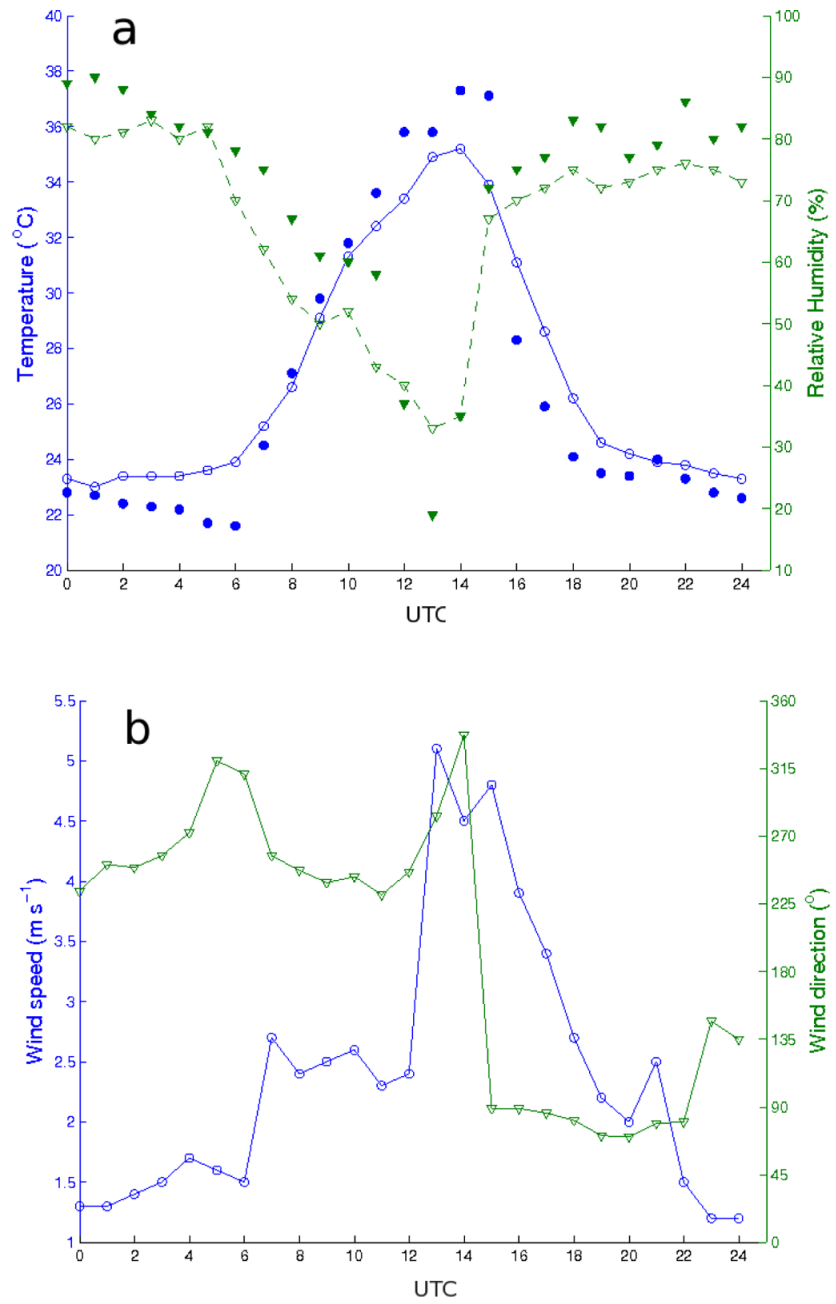

Fig. 2. Temporal evolution during 27 August 2010 of the $2 \mathrm{~m}$ (a) temperature (blue) and relative humidity (green) and (b) wind velocity (blue) and direction (green) observed at Barcelona-Fabra weather station (closed symbols) and simulated by the WRF model (line and open symbols).

wave continued, with temperatures between $20^{\circ} \mathrm{C}$ and $25^{\circ} \mathrm{C}$ at $850 \mathrm{hPa}$ in the south and southeast until 31 August 2010.

\subsection{Analysis of surface observations}

To avoid the heat island effect, data from the weather station installed at the Fabra Observatory, located $10 \mathrm{~km}$ away from the city center $(420 \mathrm{~m}$ a.s.l.) was selected. Figure 2 shows the observed (closed symbols) temporal evolution during 27 August 2010 of temperature, relative humidity, wind speed and direction. Figure 2a shows that from approximately 06:00 UTC to 12:00 UTC the temperature increased by about $2.3^{\circ} \mathrm{C} \mathrm{h}^{-1}$, from nearly $22^{\circ} \mathrm{C}$ at $05: 00$ UTC (a typical temperature value for this date and hour) to more than $36^{\circ} \mathrm{C}$ at 12:00 UTC. During this period the relative humidity dropped, from approximately $90 \%$ at $05: 00$ UTC to $20 \%$ 

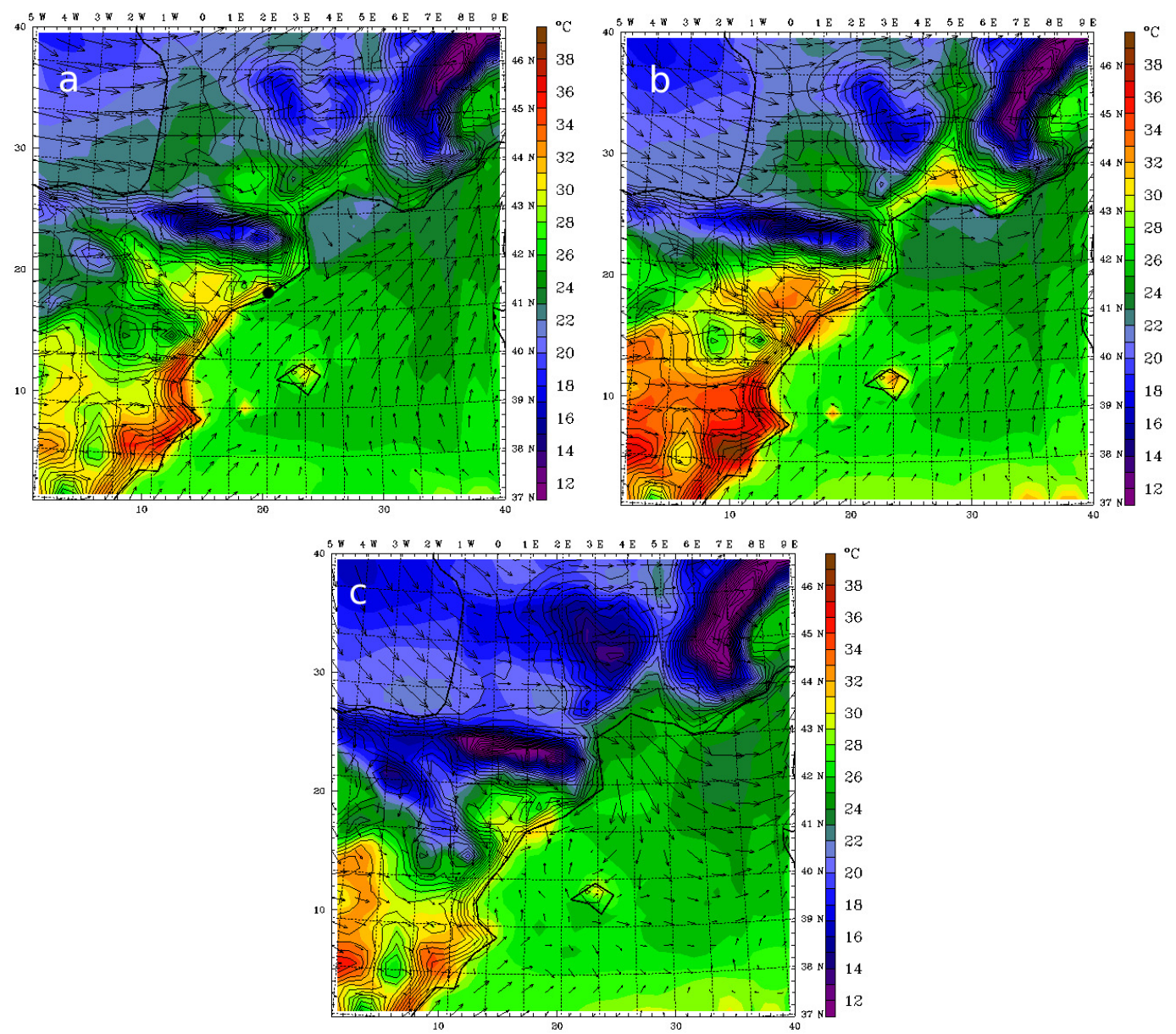

Fig. 3. Simulated $2 \mathrm{~m}$ temperature (color contour) and surface wind field (arrows) at domain 1 at (a) 10:00, (b) 15:00 and (c) 18:00 UTC on 27 August 2010. The black point in (a) indicates the location of Barcelona.

at 12:00 UTC. From noon to 16:00 UTC the relative humidity changed slightly. However, the temperature increased between 12:00 and 15:00 UTC, reaching the fifth historically highest temperature recorded since 1914 in this observatory, $38.3^{\circ} \mathrm{C}$, at 15:00 UTC. Until this hour wind direction (see Fig. $2 \mathrm{~b}$ ) was approximately constant, around $270^{\circ}$. Therefore, westerly wind advected extreme warm and dry air mass from the inland of the Iberian Peninsula.

From approximately 15:00 UTC, a change in wind direction occurred and western flow was replaced by easterly winds which removed the warm and dry air mass, advecting a relatively cold and wet Mediterranean air mass. This fact produced a decrease in temperature and a rise in relative humidity that can be clearly observed in Fig. 2a. From 15:00 UTC to 16:00 UTC, the temperature dropped from $37^{\circ} \mathrm{C}$ to $28^{\circ} \mathrm{C}$, and relative humidity rose from $20 \%$ to nearly $60 \%$. From 19:00 UTC normal values for this period of the year of temperature and relative humidity were recorded. Consequently, the change in wind direction clearly drove the evolution of temperature and relative humidity.

\subsection{Mesoscale numerical simulation}

In order to analyze the dynamics of the atmosphere that produced this rapid change of temperature and relative humidity, the version 3.3 of the Advanced Research WRF-ARW (Skamarock et al., 2008) has been used. Four nested domains were defined with respective horizontal resolutions of 27, 9, 3 and $1 \mathrm{~km}$. The smallest domain covers $70 \times 70 \mathrm{~km}^{2}$. The initial and boundary conditions were updated every six hours with data from the European Centre for Medium-Range Weather Forecast (ECMWF) operational analysis. The following parameterizations were used for the different physical processes: the Kain-Fritsch scheme in the two larger domains; no parameterization of cumulus formation in the two smallest domains; the MRF scheme for processes in the mixed layer; a simple ice scheme for the cloud microphysics; and cloud-radiation parameterization for the radiation parameterization. The simulation begins on 25 August 2010 at 00:00 UTC and finishes on 28 August 2010 at 18:00 UTC. 

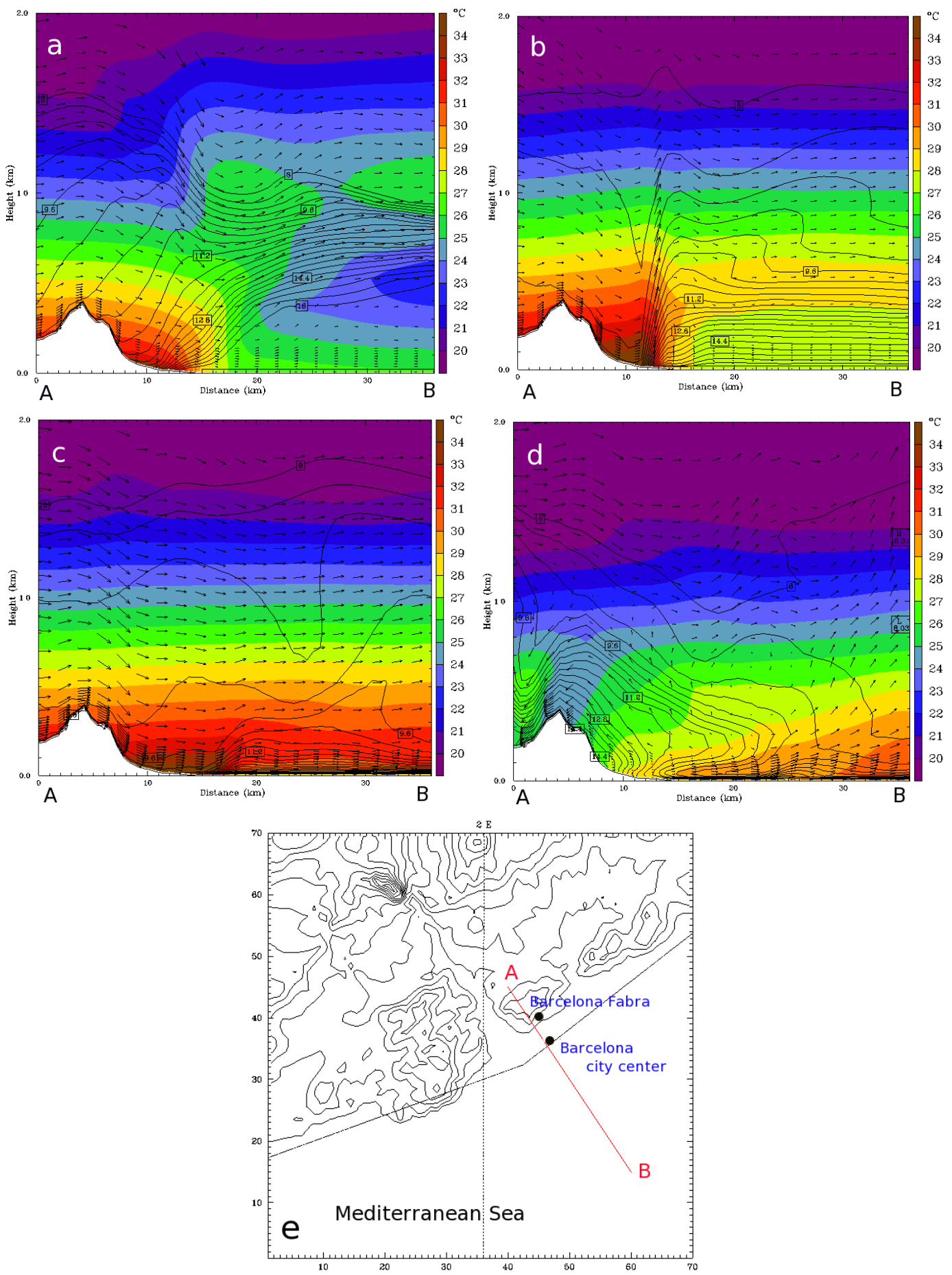

Fig. 4. (a-d) Vertical cross section along the line $A B$ shown in (e) of the simulated temperature (color contour), water vapor-mixing ratio (black lines) and wind field (arrows) at (a) 10:00, (b) 12:00, (c) 15:00, and (d) 18:00 UTC on 27 August 2010. (e) Orography of the smallest domain of the simulation.

In order to validate the simulation, Fig. 2 also shows the WRF simulated temperature, relative humidity, wind speed and direction (line and open symbols) at the nearest point of the model to the Fabra weather station. Both simulated temperature and relative humidity fit well the observed values. However, some discrepancies can be noticed in the maximum values. The maximum simulated temperature is around $35^{\circ} \mathrm{C}$, almost $3{ }^{\circ} \mathrm{C}$ less than the observed value. In 
addition, at 05:00 and 06:00 UTC the simulated temperature is around $3{ }^{\circ} \mathrm{C}$ higher than the observed one. Moreover, the simulated relative humidity overestimates the observed value at 15:00 UTC. The simulated wind velocity and direction (not shown) also fit well the observations, except the rapid change in wind direction recorded from 15:00 UTC that occurs slowly in the WRF simulation.

According to the analysis of the simulation in domain 1 during 25 and 26 August 2010 (not shown), a warm air mass was located in the southern part of the Iberian Peninsula. On 27 August a west and southwest synoptic flow advected the warm air mass from the center and south of the Iberian Peninsula to the east and northeast region, where the maximum values of temperature were recorded on 27 August.

Figure 3 shows the simulated $2 \mathrm{~m}$ temperature (color contour) and the surface wind field (arrows) at the largest domain at different hours on 27 August 2010. West and southwest synoptic flow advected warm and dry air mass from the center of the Iberian Peninsula to the northeast coast. The simulated maximum temperatures at 10:00 UTC (see Fig. 3) were located at the Mediterranean coast, with values of around 33$36^{\circ} \mathrm{C}$ at the eastern and southeastern area, and $30-33^{\circ} \mathrm{C}$ at the northeastern area, in agreement with the observed values by AEMET. During that day the intensity of the westerly flow prevented the formation of the sea breeze that usually helps to keep the temperature at moderate values in this area. At 15:00 UTC (Fig. 3b) the westerly flow increased and the maximum recorded temperatures rose to $40^{\circ} \mathrm{C}$ in many places of the coastline. According to the simulation, a northern advection affected the northern part of the Iberian Peninsula between 17:00 and 18:00 UTC. In this type of synoptic configuration, the flow turned northeast and east at the northeast coast of the Iberian Peninsula. At 18:00 UTC (Fig. 3c) a relative cold and wet air mass from the northeast and east swept the warm and dry air mass, which cooled and moistened the air, decreasing the temperature to the usual values.

Figure $4 \mathrm{a}-\mathrm{d}$ show the vertical cross section of temperature and water vapor-mixing ratio along the line $\mathrm{AB}$ defined in Fig. 4e at different hours. At 10:00 UTC (Fig. 4a) a cold and dry air mass from the southwest arrives at the Mediterranean coastline, which remains stationary for approximately $4 \mathrm{~h}$ (from 10:00 to 14:00 UTC). The relatively cold and wet Mediterranean air mass avoids the offshore displacement of the warm and dry air mass. Notice how at the boundary between both masses, the warmest one rises vertically over the coldest one. At 12:00 UTC (Fig. 4b) a large gradient in temperature and humidity appears at the coastline of Barcelona. The simulated $2 \mathrm{~m}$ temperature reached more than $35^{\circ} \mathrm{C}$ (see Fig. 4a) and the water vapor-mixing ratio lowered to $9 \mathrm{~g} \mathrm{~kg}^{-1}$. Around $10 \mathrm{~km}$ offshore from the coastline, the $2 \mathrm{~m}$ simulated temperature is around $26^{\circ} \mathrm{C}$ and the water vapor-mixing ratio is around $16 \mathrm{~g} \mathrm{~kg}^{-1}$. The height of the accumulated warm air mass is estimated by looking at Fig. 4b, which is around $600 \mathrm{~m}$. At 15:00 UTC (Fig. 4c) the warm air moves offshore and displaces the relatively
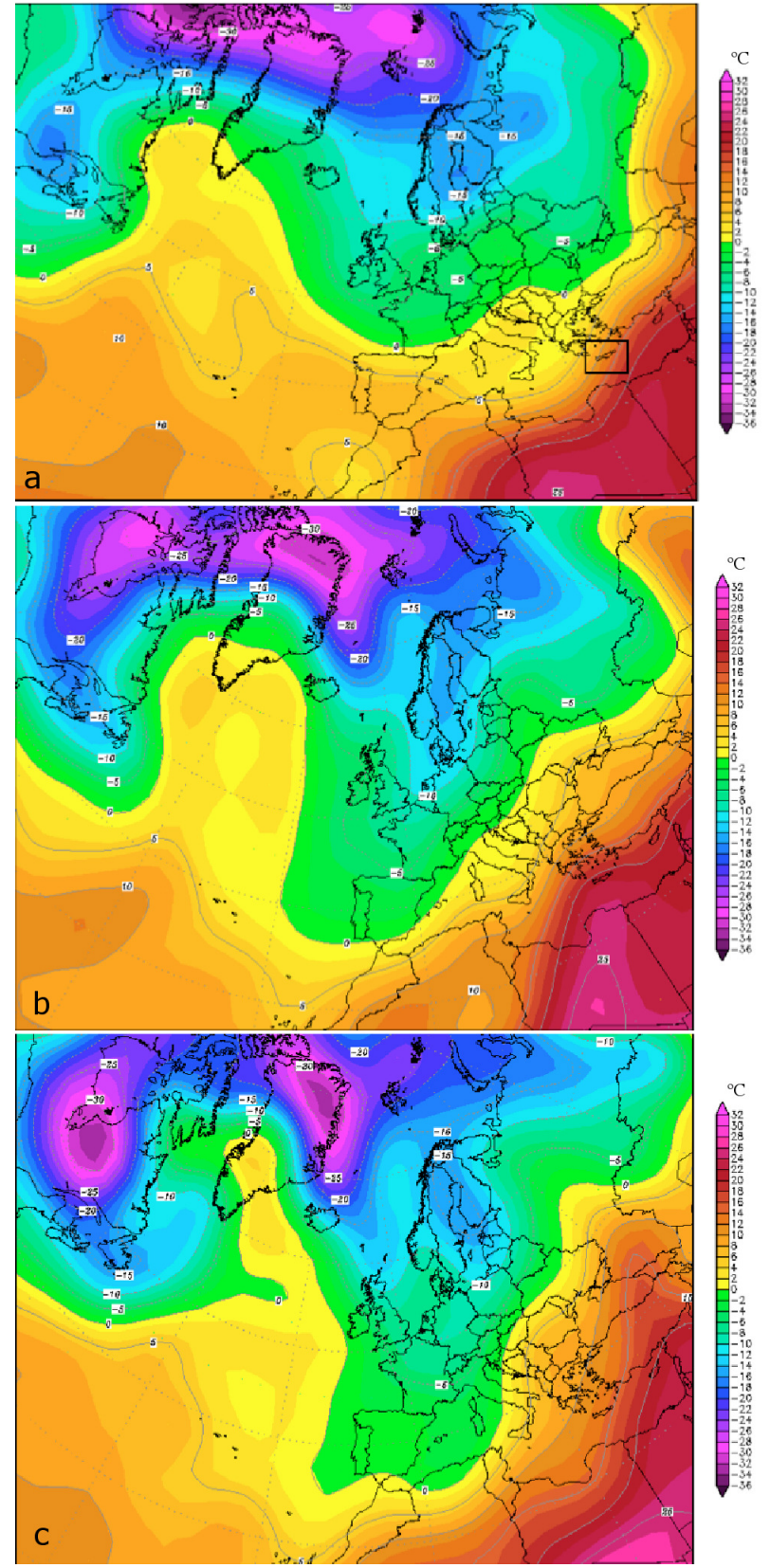

Fig. 5. Temperature at $850 \mathrm{hPa}$ obtained by the NCEP reanalysis at 00:00 UTC on (a) 22, (b) 23 and (c) 24 March 2008. The black square in (a) is centered over Crete.

cold and wet Mediterranean air mass. This situation changed from 18:00 UTC, as is shown in Fig. 4d. The north advection shown in Fig. $5 c$ ruled to the east at the Barcelona area, moistening and cooling the air while mixing the different layers and breaking the stratification. At 20:00 UTC (not shown) the maritime flow restored the values of temperature and relative humidity. 
Table 2. Values of the average of the absolute maximum temperature, the average of the maximum monthly temperature and the 60th percentile of the average of the maximum monthly temperature recorded during the period 1961-1990 at the Barcelona-Fabra weather station (Barcelona).

\begin{tabular}{lrrr}
\hline Month & $\begin{array}{r}\bar{T}_{\text {max-abs }} \\
\left({ }^{\circ} \mathrm{C}\right)\end{array}$ & $\begin{array}{r}\bar{T}_{\max } \\
\left({ }^{\circ} \mathrm{C}\right)\end{array}$ & $\begin{array}{r}p 60 \bar{T}_{\max } \\
\left({ }^{\circ} \mathrm{C}\right)\end{array}$ \\
\hline July & 32.6 & 27.6 & 28.6 \\
August & 31.6 & 26.7 & 27.6 \\
\hline
\end{tabular}

\subsection{Flash heat definition and occurrence}

According to the evolution of temperature observed during 27 August 2010 at the Barcelona area, a definition of flash heat event is suggested. An event of rapid increase of temperature could be considered as a flash heat if the following conditions are fulfilled:

1. The maximum daily temperature $\left(T_{\max }\right)$ exceeds by at least by $5^{\circ} \mathrm{C}$ the absolute maximum temperature $\left(\bar{T}_{\text {max-abs }}\right)$ averaged during the considered month in the period 1960-1990 $\left(T_{\max }>5+\bar{T}_{\max -\mathrm{abs}}\right)$. This criterion follows the definition of heat wave by the WMO.

2. The temperature $24 \mathrm{~h}$ prior to and later than the extreme temperature recorded $\left(T_{24}\right)$ does not exceed the monthly average of the absolute maximum temperature $\left(T_{24}<\bar{T}_{\max -\mathrm{abs}}\right)$. This criterion assures that the maximum temperature the day before and after the maximum daily temperature recorded remains in average values.

3. The temperature $12 \mathrm{~h}$ prior to and after the extreme temperature recorded $\left(T_{12}\right)$ does not exceed the 60th percentile of the monthly maximum average temperature $\left(T_{12}<p 60 \bar{T}_{\max }\right)$.

By using these criteria, Table 2 shows the $\bar{T}_{\text {max }}, \bar{T}_{24}$, and $\bar{T}_{12}$ for a flash heat event during July and August by using the recorded values at Fabra weather station during the period 1961-1990.

According to these data, a flash heat event occurs during these summer months if:

1. The maximum daily temperature exceeds $37.6^{\circ} \mathrm{C}$ in July and $36.6^{\circ} \mathrm{C}$ in August.

2. The temperature $24 \mathrm{~h}$ prior to and after the maximum daily recorded temperature does not exceed $32.6^{\circ} \mathrm{C}$ in July and $31.6^{\circ} \mathrm{C}$ in August.

3. The temperature $12 \mathrm{~h}$ prior to and after the maximumrecorded temperature does not exceed $28.6^{\circ} \mathrm{C}$ in July and $27.6{ }^{\circ} \mathrm{C}$ in August.
Table 3. Most significant flash heat episodes affecting Barcelona since 1780. Note that on 27 of August 2010, the maximum temperature was $39.3{ }^{\circ} \mathrm{C}\left(24^{\circ} \mathrm{C}\right.$ in the early morning and $26^{\circ} \mathrm{C}$ in the evening). $T_{12-}$ and $T_{12+}$ indicate the temperature $12 \mathrm{~h}$ before and after the maximum temperature recorded $\left(T_{\max }\right)$, respectively.

\begin{tabular}{lrrrl}
\hline Date & $\begin{array}{r}T_{\max } \\
\left({ }^{\circ} \mathrm{C}\right)\end{array}$ & $\begin{array}{r}T_{12}- \\
\left({ }^{\circ} \mathrm{C}\right)\end{array}$ & $\begin{array}{r}T_{12+} \\
\left({ }^{\circ} \mathrm{C}\right)\end{array}$ & $\begin{array}{l}\text { Wind } \\
\text { direction }\end{array}$ \\
\hline 1 July 1790 & 36 & 23.5 & 25 & SW \\
10 July 1820 & 34.4 & 21 & 26.5 & SW \\
27 July 1843 & 35.5 & 23.5 & 24 & SSW-SW \\
5 August 1846 & 35.5 & 26 & 27 & $\mathrm{~S}$ \\
15 July 1859 & 35 & 27 & 26 & SSW-SW \\
17 August 1881 & 35.5 & 25 & 26 & SSW \\
13 July 1896 & 36 & 21 & 22 & SW \\
\hline
\end{tabular}

To know the frequency of these types of events, the definition of a flash heat event has been applied to the daily temperature series of Barcelona starting from 1780. Although the series is not homogeneous (Mazon et al., 2011), a first approach to flash heat events is possible by looking into a partial series of the daily temperature record. Table 3 shows some events detected as a flash heat during the 18th and 19th centuries.

\section{The 23 March 2008 event (Heraklion event)}

The island of Crete, located in the Middle Eastern area of the Mediterranean Sea, near the North African coastline and consequently to the Sahara, used to be affected by advection of warm and dry air masses from the Sahara, also associated with intense dust events (Kaskaoutis et al., 2008; Fotiadi et al., 2006; Moulin et al., 1998). This advection produces an increase of temperature that only lasts several hours, especially on the northern side of the island (Nastos, personal communication). Consequently, this type of event cannot be classified as a heat wave.

An event with similar atmospheric dynamics that occurred to the north of Italy was studied by Gladich et al. (2008). They analyze an unusual and sudden increase of temperature during the night that lasted more than $1 \mathrm{~h}$, not associated with thunderstorm processes, but induced by orography. In our opinion the studied event is not a heat burst or a heat wave. It is associated with a rapid and sudden increase of temperature in a intermediate scale between the two.

\subsection{Synoptic situation}

On 21 March 2008 a low-pressure area was placed over southern Greece, around $1005 \mathrm{hPa}$ at sea level (not shown), producing a southwesterly advection to the Island of Crete. On 22 March this low pressure moved to southern Turkey. At sea level, a southeast flow affected Crete. Figure 5 shows the temperature at $850 \mathrm{hPa}$ obtained by the NCEP reanalysis 


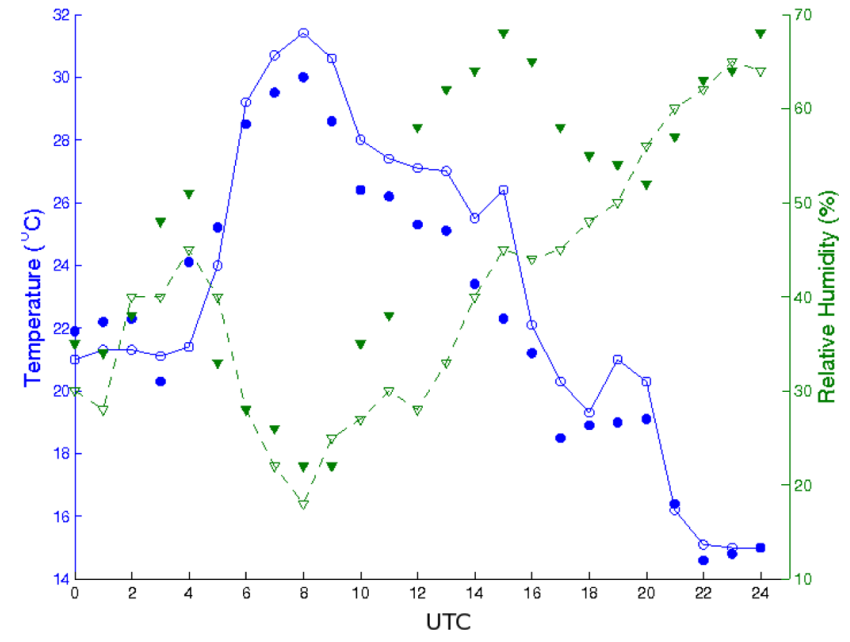

Fig. 6. Temporal evolution during 23 March 2008 of the $2 \mathrm{~m}$ temperature (blue) and relative humidity (green) observed at the Heraklion weather station (closed symbols) and simulated by the WRF model (line and open symbols).

on 22, 23 and 24 March 2008 at 00:00 UTC. On 22 March (Fig. 5a) a warm air mass was located over North Africa. A ridge moved on 23 March to the north, affecting the whole island of Crete (Fig. 5b). On 24 March, the ridge moved out to the south (see Fig. 5c).

\subsection{Analysis of surface data}

Data from the automatic weather station $(39 \mathrm{~m}$ a.s.l., $35^{\circ} 19^{\prime} \mathrm{N}, 25^{\circ} 10^{\prime}$ E) placed near Heraklion is used to detect this flash heat event, and to validate the mesoscale numerical simulation. Figure 6 shows the temporal evolution during 23 March 2008 of the observed temperature and relative humidity (closed symbols). During the early morning the observed temperature shows a large increase from 03:00 UTC, reaching $30.2{ }^{\circ} \mathrm{C}$ at $08: 00 \mathrm{UTC}$. Relative humidity shows a large drop from 04:00 UTC, reaching the minimum value around $20 \%$ at 08:00 UTC. From 10:00 UTC, temperature decreases and relative humidity increases gradually. Nastos et al. $(2011,2013)$ analyze this event as described from a biometeorological point of view.

\subsection{Mesoscale numerical simulation}

WRF mesoscale model has been used to analyze the dynamics of the atmosphere that produced this rapid change of temperature and relative humidity. Three nested domains were defined with horizontal resolutions of 18,6 , and $2 \mathrm{~km}$. The smallest domain covers $150 \times 150 \mathrm{~km}^{2}$. ECMWF operational analysis was used to provide the initial and boundary conditions every 6 hours. The same physical parameterizations enumerated in Sect. 2.3 were used for the mesoscale simulation of this event. The simulation begins on 22 March 2008 at 00:00 UTC and finishes on 24 March at 18:00 UTC.
The simulated evolution of $2 \mathrm{~m}$ temperature (blue line and open circles) and relative humidity (green dashed line and open triangles) at the nearest point of the model to the Heraklion weather station is also shown in Fig. 6. WRF simulation overestimates (around $2{ }^{\circ} \mathrm{C}$ ) the observed temperature between 07:00 to 16:00 UTC. However, the simulated relative humidity shows a remarkable difference to the recorded values, especially from 11:00 to 19:00 UTC. While the recorded values of relative humidity between 11:00 and 17:00 UTC are around $70 \%$, the simulated values are lower than $50 \%$.

Figure 7 shows the simulated $2 \mathrm{~m}$ temperature (color contours) and surface wind field (arrows) at the smallest domain for several hours on 23 March 2008. At 00:00 UTC (Fig. 7a) the simulation shows a southeasterly flow over the southern coast of Crete, where the temperature is around $17^{\circ} \mathrm{C}$. However, on the northern side a higher temperature, between $24^{\circ} \mathrm{C}$ and $28^{\circ} \mathrm{C}$ is simulated. At 04:00 UTC (Fig. 7b) the southeasterly wind ruled to southerly; the warm and dry air mass associated with the North Africa advection, which can be considered as a warm front, lifted over the relatively cold sea air around $70 \mathrm{~km}$ offshore the southern coastline of the island. Consequently, the temperature remained around $17^{\circ} \mathrm{C}$ on the southern coastline of the island. This large thermal difference between both faces is even larger at 08:00 UTC (Fig. 7c), when the simulated temperature shows the higher values at the north face, around $31^{\circ} \mathrm{C}$ (at the southern face the temperature remained between 20 and $23^{\circ} \mathrm{C}$ ). From 11:00 UTC the temperature began to decrease. As shown in Fig. $7 \mathrm{~d}$, during the afternoon the temperature shows normal values on both sides of the island.

Figure 8a-d shows the temperature and water vapormixing ratio along the line $\mathrm{AB}$ shown in Fig. 8e. During the early morning on 23 March 2008, the warm and dry air mass is lifted over the relatively cold and wet Mediterranean air mass, which remained on the southern side of the island (Fig. 8a). On the southern side of the island the temperature at sea level remained around $20^{\circ} \mathrm{C}$ due to the influence of the cold sea air. However, on the northern side the temperature increases, reaching $25^{\circ} \mathrm{C}$ at many areas due to strong descending air not associated with a Foehn effect. The warming at the north coast of the island is associated with an air mass of the same characteristics as the African air mass that descends (vertical wind speed on the northern side was around $-1 \mathrm{~ms}^{-1}$ ) once the colder Mediterranean air mass located at the southern coast is overpassed. For this reason this air mass only affects the north side of the island.

The thermal difference between the northern and the southern coasts of the island increased in the hours that passed. At 07:00 UTC (Fig. 8b) the simulated temperature reached $31^{\circ} \mathrm{C}$ at Heraklion (north side) while on the southern side the temperature remained around $20^{\circ} \mathrm{C}$. The largest value in the thermal difference between the northern and the southern sides of the island occurred around 10:00 UTC (Fig. 8c). The simulated temperature on the northern side reached $31.8^{\circ} \mathrm{C}$ at sea level, with $4.5 \mathrm{~g} \mathrm{~kg}^{-1}$ 

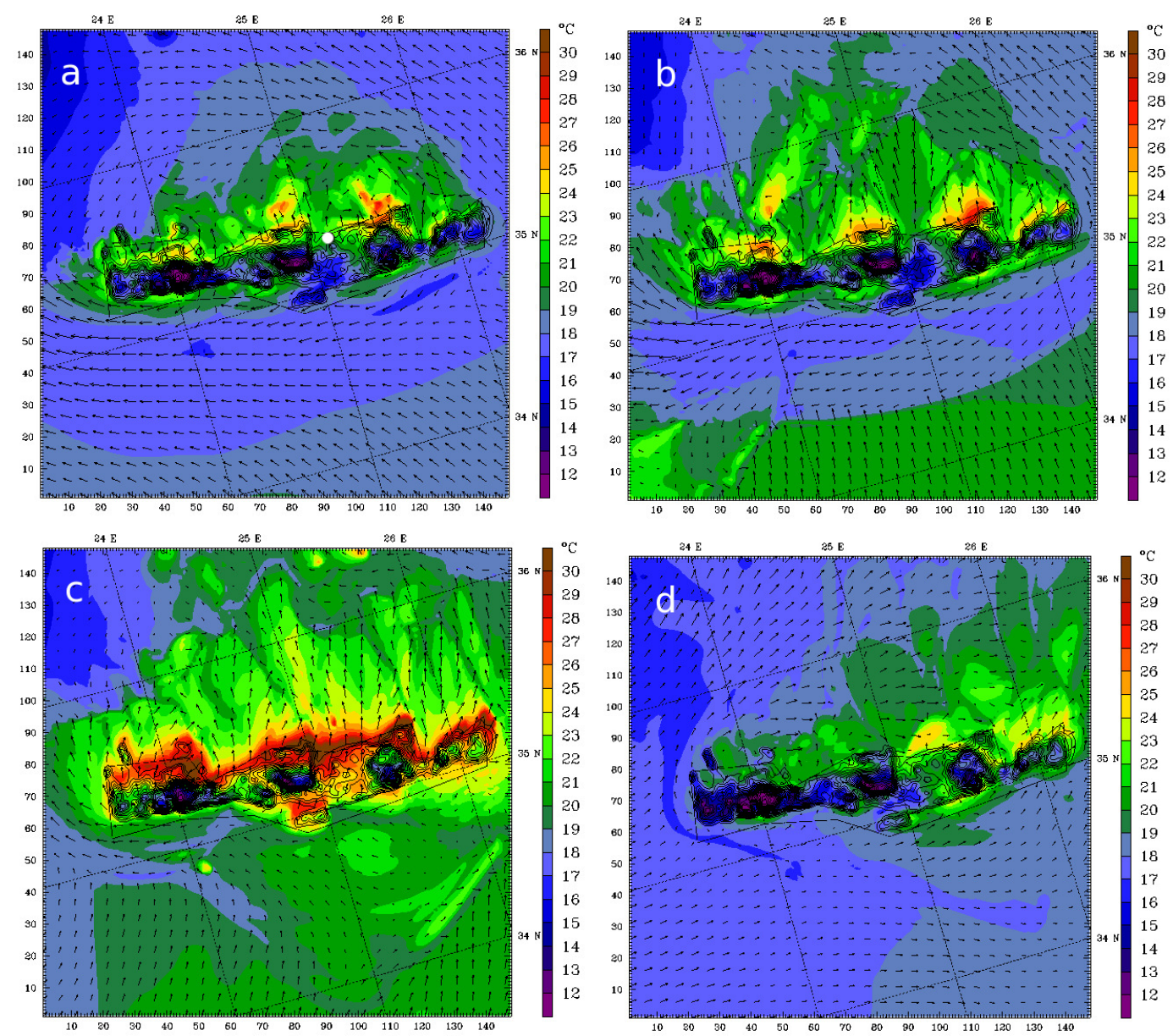

Fig. 7. Simulated $2 \mathrm{~m}$ temperature (color contour) and surface wind field (arrows) at domain 3 at (a) 00:00, (b) 04:00, (c) 09:00 and (d) 17:00 UTC on 23 March 2008. The white point in (a) indicates the location of Heraklion.

of water vapor-mixing ratio. On the southern side, the air temperature reached $21.3^{\circ} \mathrm{C}$ and around $9 \mathrm{~g} \mathrm{~kg}^{-1}$ in the water vapor-mixing ratio. A change in the wind direction from 14:00 UTC restored the normal values for both temperature and relative humidity. At 16:00 UTC (Fig. 8d) the simulated temperature and water vapor-mixing ratio at both coasts are similar, around $22^{\circ} \mathrm{C}$ and $9 \mathrm{~g} \mathrm{~kg}^{-1}$, respectively.

\section{Potential risk and impacts of flash heats}

Flash heat events, a rapid increase of temperature, which lasts less than $24 \mathrm{~h}$ but more than 1 hour, could be associated with a variety of effects to human health or discomfort, economic activities, and the environment (air quality).

According to data from the main Spanish electric company (Endesa), at midday on 27 August 2010 (Barcelona event), a new record in electricity consumption was recorded: during a few hours, around $38000 \mathrm{MW}$ were required throughout the whole country. The day before and after, consumption did not reach $23000 \mathrm{MW}$. The power network was working $64 \%$ more than any other normal day for that period.

Moreover, most of the big wild fires in the Mediterranean are produced by a combination of high temperature and low relative humidity (Millan et al., 1998). Consequently, flash heat events are likely to be one of the main risks in triggering wild fires because the drop in relative humidity and increase in temperature contribute to drying the vegetation.

Probably one of the most affected sectors during a flash heat event is agriculture. Unlike what happens during a heat wave, when temperature and relative humidity changes slowly gradually and some measures (e.g. to irrigate to decrease water stress) can be taken in order to avoid its impact, during a flash heat the changes are more abrupt. For instance, during the flash heat event on 27 August 2010 several regions in the northeast of the Iberian Peninsula lost around the $20 \%$ of their grape production. Grapes are very sensitive to a sudden increase in temperature and drop in relative humidity, causing the fruit to lose a lot of internal water. After the event, the process cannot be restored and the production of 

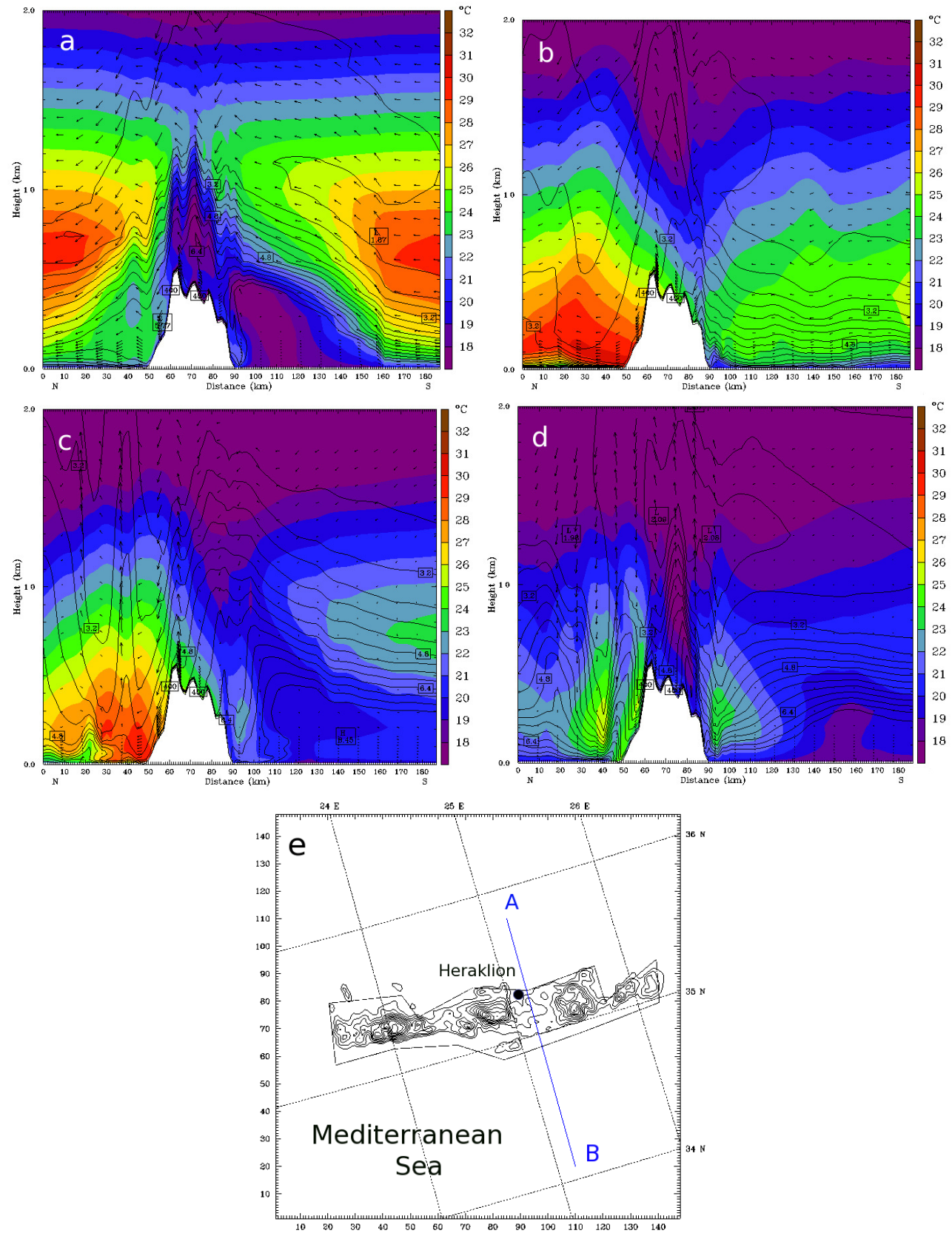

Fig. 8. (a-d) Vertical cross section along the line AB defined in (e) of the simulated temperature (color contour), water vapor-mixing ratio (line contour) and the wind field (arrows) on 23 March 2008 at (a) 04:00, (b) 07:00, (c) 10:00 and (d) 16:00 UTC. Orography of the smallest domain of the simulation.

wine is greatly disturbed in the quantity as well as the quality of wines (personal communication with the Torres wine company, 2010).

Concerning the air quality, as with the heat waves, the rapid rise of temperature associated with flash heat can be associated with an increase of pollutants and ozone concentration.

\section{Conclusions}

According to WMO and AMETSOC, as well as several national weather services, heat wave is defined as an abnormal period of higher temperatures over 2 or more days. In addition, AMETSOC defines a heat burst as a rapid increase in temperature that takes place over a period of minutes, usually associated with downstream flows occurring during storms or because of local Foehn effects. Thus, the events described in 
this paper are not a heat wave or burst. We propose naming this type of event flash heat.

The first analyzed flash heat occurred on 27 August 2010 at the northeast area of the Iberian Peninsula due to a rapid and sudden advection of a warm and dry air mass from North Africa that affected this area for around $12 \mathrm{~h}$. The analysis of data from automatic weather stations located around Barcelona (northeast Iberian Peninsula) shows a rapid increase in temperature and a decrease in relative humidity after 05:00 UTC. At 13:00 UTC the temperature reached the maximum value, $39.3{ }^{\circ} \mathrm{C}$, at the city center and $38.3^{\circ} \mathrm{C}$ at the Fabra Observatory. The relative humidity decreased to $19 \%$ at the city center and around $22 \%$ at the Fabra Observatory. From 15:00 UTC the temperature decreased; and at 18:00 UTC it was less than $24^{\circ} \mathrm{C}$, i.e., within normal values for this season and time of the day.

WRF simulation shows a westerly flow over the Iberian Peninsula that advects warm and dry air over the Mediterranean coast, where the maximum temperature is simulated and in agreement with the observed values. This advection disappears to the northeast of the Iberian Peninsula and is replaced by an easterly flow that advects a relatively cold and wet air mass as it displaces the warm and dry mass onshore.

Applying the preliminary definition of flash heat to the historical temperature data series of Barcelona, we found that in the 19th century at least 13 episodes could be identified as flash heats.

The second analyzed event occurred on 23 March 2008 at the north face of the island of Crete. A rapid increase of temperature in Heraklion, a city located at the north coast of the island, caused by a strong downward flow, which keeps the characteristics of an air mass advected from Africa, has been studied and simulated. During almost $8 \mathrm{~h}$ the temperature reaches higher than average values, and relative humidity show unexpected low values. These recorded larger temperatures are due to the lift of a warm and dry African air mass caused by a colder Mediterranean air mass located on the southern coast of Crete. This fact and the mountain waves that appeared due to the orography mean that the warm air mass only affected the north side of the island, producing a large temperature difference between both coasts. From approximately 00:00 to 11:00 UTC on 23 March 2008 the temperature at Heraklion, and all over the north coast of the island reached more than $30^{\circ} \mathrm{C}$. From noon and early afternoon, when the southerly flow disappeared and veered easterly and southeasterly, the temperature decreased, having usual values for this period of the year.

From the analyses shown in this paper, flash heat events can be considered as defining those warm events within Meso- $\beta$ and $-\gamma$ scales lasting no more than $24 \mathrm{~h}$.
Acknowledgements. This project has been carried out by using the resources of the Supercomputing Center of Catalonia (CESCA) and it has been funded by the Spanish projects CGL2009-08609 and CGL2012-37416-C04-03. The NCEP images are from www.wetterzentrale.de. Observational data was provided by METEOCAT, AEMET and the Hellenic National Meteorological Service. We are also grateful to Alfons Puertas from the Fabra Observatory (Barcelona), and P. Nastos from the University of Athens for his helpful comments in the Barcelona and Heraklion events, respectively.

Edited by: A. Mugnai

Reviewed by: P. Nastos, F. Stel, and one anonymous referee

\section{References}

Egger, J. and Hoinka, K. P.: Fronts and orography, Meteorol. Atmos. Phys., 48, 3-36, 1992.

Fotiadi, A., Hatzianastassiou, N., Drakakis, E., Matsoukas, C., Pavlakis, K. G., Hatzidimitriou, D., Gerasopoulos, E., Mihalopoulos, N., and Vardavas, I.: Aerosol physical and optical properties in the Eastern Mediterranean Basin, Crete, from Aerosol Robotic Network data, Atmos. Chem. Phys., 6, 53995413, doi:10.5194/acp-6-5399-2006, 2006.

Frich, A., Alexander, L. V., Della-Marta, P., Gleason, N., Haylock, M., Klein Tank, A. M. G., and Peterson, T.: Observed coherent changes in climatic extremes during the second half of the twentieth century, Climate Res., 19, 193-212, 2012.

Gladich, I., Gallai, I., Giaiotti, D., Mordacchini, G., Palazzo, A., and Stel, F.: Mesoscale heat waves induced by orography, Adv. Sci. Res., 2, 139-143, 2008.

Glickman, T. S.: Glossary of Meteorology, American Meteorological Society, 2nd Edn., 2000.

Hamilton, J. M., Maddison, D. J., and Tol, R. S. J.: Climate change and international tourism: a simulation study, Global Environ. Change, 15, 253-266, 2005.

Hassid, S., Santamourins, M., Linardi, A., Klitsikas, N., Georgakis, C., and Assimakopoulus, D. N.: The effect of the Athens heat island on air conditioning load, J. Energy Build., 32, 131-141, 2000.

Johnson, B. C.: The Heat Burst of 29 May 1976, Mon. Weather Rev., 111, 1776-1792, 1976.

Jolly, W., Dobbertin, M., Zimmermann, N. E., and Reichstein, M.: Divergent vegetation growth responses to the 2003 heat wave in the Swiss Alps, Geophys. Res. Lett., 32, 18409-18418, 2005.

Karl, T. and Quayle, R. G.: The 1980 Summer Heat Wave and Drought in Historical Perspective, Mon. Weather Rev., 109, 2055-2073, 1981.

Kaskaoutis, D. G., Kambezidis, H. D., Nastos, P. T., and Kosmopoulos, P. G.: Study on an intense dust storm over Greece, Atmos. Environ., 42, 6884-6896, 2008.

Lise, W. and Tol, R. S. J.: Impact of climate on tourism demand, Climatic Change, 55, 429-449, 2002.

Maninns, P. C. and Sawford, B. L.: A model of katabatic wind, J. Atmos. Res., 36, 619-630, 1979.

Matzarakis, A. and Nastos, P.: Human-Biometeorological assesment of heat waves in Athens, Theor. Appl. Climatol., 105, 99106, 2010. 
Mazon, J., Barriendos, M., Prohom, M., Rodríguez, R., Blanch, A., and Ripoll, R.: Reconstruction of long temperature series of Barcelona, in: 11th EMS Annual Meeting, Berlin (Germany), 2011.

Meehl, G. A. and Tebald, C.: More intense, more frequent and longer lasting heat waves in the 21 st centuri, Science, 13, 994997, 2004

Millan, M. M., Estrella, M. J., and Badenas, C.: Meteorological processes relevant to forest fire dynamics on the Spanish Mediterranean coast, J. Appl. Meteorol., 37, 83-100, 1998.

Moulin, C., Lambert, C. E., and Dayan, U.: Satellite climatology of African dust transport in Mediterranean atmosphere, J. Geophys. Res., 103, 13137-13144, 1998.

Nastos, P. T. and Matzarakis, A.: The effect of air temperature and human thermal indices on mortality in Athens, Theor. Appl. Climatol., 108, 591-599, 2012.

Nastos, P. T., Bleta, A. G., Kampanis, N. A., Giaouzaki, K. N., and Matzarakis, A.: Environmental impacts on human health during a Saharian dust episode at Crete Island, Greece, Meteorol. Z., 20, 517-529, 2011.

Nastos, P. T., Bleta, A. G., and Matsangouras, I. T.: The development of Fohn winds due to Saharan Dust Outbreaks and the associated human thermal bioclimatic conditionsin Crete island, Greece, in: Proceedings of the 13th international Conference on Environmental Science and Technology, Athens (Greece), 2013.
Orlanski, I.: A rational subdivision of scales for atmospheric processes, B. Am. Meteorol. Soc., 56, 527-530, 1975.

Skamarock, W. C., Klemp, J. B., Dudhia, J., Gill, D. O., Barker, D. M., Duda, M., Huang, X.-Y., W., W., and Powers, J. G.: A Description of the Advanced Research WRF Version 3, Tech. Rep. TN-475+STR, NCAR, 2008.

Smoyer-Tomic, K. E., Khun, R., and Hudson, A.: Heat wave hazards: an overview of heat waves impacts in Canada, Nat. Hazards, 28, 465-486, 2003.

Steadman, R. G.: A universal scale of apparent temperature, J. Clim. Appl. Meteorol., 23, 1674-1687, 1984.

Trenberth, K. E., Jones, P. D., Ambenje, P., Bojariu, R., Easterling, D. Klein Tank, A., Parker, D., Rahimzadeh, F., Renwick, J. A., Rusticucci, M., Soden, B., and Zhai, P.: Observations: Surface and Atmospheric Climate Change, in: Contribution of Working Group I to the Fourth Assessment Report of the Intergovernmental Panel on Climate Change, 2007, edited by Solomon, S., Qin, D., Manning, M., Chen, Z. Marquis, M., Averyt, K. B., M., T., and Miller, H. L., Cambridge University Press, Cambridge, United Kingdom and New York, NY, USA, 2007.

Wakonigg, H.: The north foehn in the south-eastern Alpine border zone, Mitt. Oesterr. Geol. Ges., 132, 27-55, 1990. 